\title{
How Public Trust and Healthcare Quality Shape Blood Donation Behavior: Comparative Evidence
}

\author{
Caroline Graf ${ }^{*} \dagger$, Bianca Suanet ${ }^{\ddagger}$, Pamala Wiepking ${ }^{\S, *}$ \\ and Eva-Maria Merz ${ }^{*, \dagger, \mathbb{I}}$
}

\begin{abstract}
Objective: Blood donors are indispensable for enabling a myriad of medical procedures and treatments. Although blood donation takes place in a medical setting within the larger healthcare system, little is known about how (perceptions of) these healthcare systems shape an individual's decision to donate. In this study, we examined how public trust in the healthcare system and indicators of healthcare quality relate to individuals' likelihood of donating blood across Europe. Methods: We employed large-scale survey data on blood donation behavior from representative samples of 28 European countries $(\mathrm{N}=27,868)$. This dataset was combined with country-level data on public trust in the healthcare system and healthcare quality. We used multilevel models to examine the effects of individual- and country-level factors on individual-level blood donation behavior. Results: Our preregistered analyses revealed that public trust was positively associated with donating blood. That is, individuals living in countries where trust in the healthcare system is higher were more likely to have donated blood. However, we found no clear evidence that healthcare quality predicted blood donation. Notably, most countries exhibited a decrease in public trust in the healthcare system while healthcare quality increased over time. Conclusions: Our results suggest that subjective perceptions of the healthcare system (i.e., public trust), rather than the objective state of healthcare, play a role for blood donation behavior. We highlight the implications of our findings for vital blood collection efforts in light of the observed erosion of public trust over time.
\end{abstract}

Keywords: blood donation | public trust | healthcare quality | comparative evidence

\footnotetext{
${ }^{*}$ Center for Philanthropic Studies, Dept. of Sociology, Vrije Universiteit Amsterdam

${ }^{\dagger}$ Dept. of Donor Medicine Research, Sanquin Research

${ }^{\ddagger}$ Dept. of Sociology, Vrije Universiteit Amsterdam

$\S$ Lilly Family School of Philanthropy, Indiana University-Purdue University Indianapolis

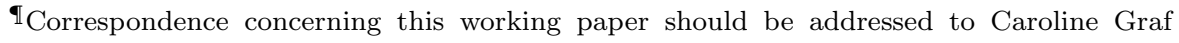
(c.graf@vu.nl).
} 
E nsuring a continuous and sufficient supply of blood is crucial for all societies, as blood plays an essential part in many medical procedures (e.g., surgeries, cancer treatment) and for producing life-saving drugs. Since blood cannot (yet) be artificially produced or stockpiled, blood collectors rely on willing donors to give their blood. These blood donations take place in a medical setting and are embedded within the larger healthcare system, i.e., donations are collected by health professionals who also monitor donor health, and blood banks coordinate the supply and demand of blood with hospitals. The specific medical context in which individuals donate blood may vary across regions and countries, because countries organize blood collection differently (Healy, 2000). Countries also differ in their healthcare systems and overall quality of healthcare (Fullman et al., 2018). Indeed, the manner in which these specific (organizational) environments affect individuals' decisions to donate blood has become an important topic of research (Healy, 2000; Gorleer et al., 2020) and accordingly the importance of the context in which the donation takes place has been recognized (Masser et al., 2020). But blood collecting institutions do not only vary in their organization of blood collection, they also vary with respect to the cultural setting in which they operate. The beliefs, values, and social norms prevalent in a given cultural setting have been shown to play a key role in shaping the social behavior of individuals (Inglehart, 2000; Hofstede, 2001; Henrich et al., 2010). Yet, despite this prevalent role of cultural factors in influencing behavior in other domains, there have thus far been only few studies examining how these factors affect human substance donation (but there are exceptions, e.g., Tison et al., 2007; De Kort et al., 2010; Gillum and Masters, 2010; Merz et al., 2016). The current study contributes to this growing literature by examining how characteristics of the healthcare system, including cultural attitudes toward the system, relate to blood donation behavior.

We focus on two characteristics of the healthcare system specifically: People's perception of the healthcare system (i.e., public trust in the healthcare system) and more objective measures of the performance of the healthcare system (i.e., quality of healthcare). Higher healthcare quality should be associated with lower (perceived) medical risks and higher (perceived) effectiveness of healthcare services in general and those pertaining to blood donation in particular. Although blood donation is usually safe, common deterrents to donating still include fear of medical errors and hospitals (Boulware et al., 2002; Klinkenberg et al., 2021). Such fears and perceived health risks can in turn deter individuals from donating blood (Masser et al., 2011). Similarly, the perceived effectiveness of blood banks has been shown to be an important factor influencing donation behavior. People are more motivated to donate blood when they perceive the blood bank to operate efficiently and donations to proceed swiftly and smoothly (Giles et al., 2004; Masser et al., 2008). Hence, we expect higher healthcare quality to be associated with higher propensity of individuals to donate blood. However, a direct link between healthcare quality and blood donation behavior has to our knowledge not been established. Nonetheless, indirect evidence for such a relationship exists. In countries with higher life expectancy (which is indicative of better healthcare quality), people perceive the procedure of blood transfusions to be safer (Merz et al., 2016). In turn, perceived blood transfusion safety was found to predict blood donation willingness (Huis in 't Veld et al., 2019).

When people live in a country with higher public trust in the healthcare system, this should also have positive effects on people's perceptions of the risks related to blood donation and efficacy of healthcare institutions, including those responsible for collecting blood. In fact, trust is an important motivating factor for blood donors but is typically studied at the individual level. That is, individual-level generalized 
trust (Boenigk et al., 2015; Merz et al., 2017) as well as individual-level trust in blood collection agencies (Chen, 2017) have been positively associated with blood donation behavior. Here we focus on public trust in the healthcare system measured at the country-level. Public trust in healthcare reflects more than an individual's experience with the healthcare system, for example by interacting with individual physicians. Instead, it is a product of how the healthcare system is portrayed in the media and how experiences are debated in the public discourse, in addition to "objective" characteristics of the system and individuals' experiences in it (Gille et al., 2017). Public trust in the healthcare system has been shown to play a key role in the effective functioning of healthcare systems, as well as for individual-level health outcomes (Gilson, 2003; Abbott and Freeth, 2008; Pilgrim et al., 2010; Gille et al., 2015; Cuevas et al., 2019; Scherer et al., 2021). For example, distrust in the healthcare system predicted higher susceptibility to health misinformation (Scherer et al., 2021), and played a key role in vaccine hesitancy during the ongoing COVID-19 pandemic (Vergara et al., 2021). It remains to be seen whether public trust in the healthcare system also shapes blood donation behavior.

Based on these findings from the previous literature, we formulate the following hypotheses to be tested in the current study.

- $\quad$ H1: Higher country-level trust in the healthcare system is associated with higher individual-level propensity to donate blood.

- H2: Higher country-level quality of healthcare is associated with higher individual-level propensity to donate blood.

\section{Materials and Methods}

We preregistered ${ }^{1}$ our hypotheses and analysis plan on the Open Science Framework (OSF; link). Our OSF repository also contains all data and code for running our analyses (link).

\section{Participants and procedure}

We employed comparative data from the 2014 wave of the Eurobarometer (European Commission, 2018), a repeated cross-sectional survey conducted among representative samples from European Union member states. In 2014, the survey was performed in 28 countries. A multi-stage random (probability) sampling design was employed and approximately 1,000 face-to-face interviews were completed in each of the countries. Respondents were residents in the respective country, had sufficient command of the national language(s), and were 15 years or older. Study protocols were approved by the European Commission and all participants provided informed consent. A detailed description of all variables, including the wording of survey items and measurement scales, is presented in Table S1. All categorical variables, including the dependent variable, are dummy-coded.

\footnotetext{
${ }^{1}$ Due to systematic variation of country-level indicators over time, we deviated from the preregistration in one respect by additionally including survey wave random effects in all models.
} 


\section{Dependent variable}

Blood donation. The dependent variable in our analyses is blood donation during one's lifetime (yes/no). Participants in the Eurobarometer were asked whether they have ever donated substances of human origin, including blood.

\section{Independent variables}

Public trust in the healthcare system. We measured country-level public trust in the healthcare system by employing survey data from the 1999 and 2008 rounds of the European Values Survey (EVS, 2021). The EVS asked respondents from all European countries about their confidence in different institutions, including the healthcare system. The term confidence is sometimes used when the target of trust is an institution instead of an individual (this is also termed institutional trust or system trust; PytlikZillig and Kimbrough, 2016). In this study we use the term public trust. In order to calculate country-level public trust for each of the European countries, we aggregated individual responses to the question: "How much confidence do you have in the healthcare system?" at the country-level. The original EVS item was on a 4-point scale (none at all; not very much; quite a lot; a great deal), which we coded as $1 ; 2 ; 3$; 4; Hence the range of the country-level indicator was from 1 to 4 . Data from the EVS on trust in the healthcare system is available for all $28 \mathrm{EU}$ countries included in our main analyses for the years 1999 and 2008 (except Cyprus for 1999).

Quality of Healthcare. We took a two-fold approach to operationalizing countrylevel quality of healthcare. That is, we included (a) the healthcare access and quality index (HAQ; Global Burden of Diseases Collaborative; Fullman et al., 2018) as a measure of how well a country manages to prevent amenable deaths and (b) a measure capturing healthcare expenditures relative to a country's gross domestic product (GDP; World Health Organization Global Health Expenditure database; World Health Organization, 2015). More specifically, the HAQ index is a globally comparable combined index reflecting the extent of amenable mortality (i.e., death rate from 32 causes of death that should not occur if medical care is effective, e.g. tuberculosis or diphtheria) across 195 countries and territories. The index ranges from 0 to 100 , where 0 (100) reflects the lowest (highest) observed levels of disease prevention across countries from 1990 to 2015. The HAQ index is available for all European countries included in our sample for the years 1990, 1995, 2000, 2005, 2010, and 2015. The WHO indicator for healthcare expenditures per GDP is a measure of total healthcare expenditure (i.e., both public and private spending on preventive and curative health services) relative to a country's GDP. The theoretical range of this indicator is from $0 \%$ to $100 \%$ of GDP. Healthcare expenditure is available for all countries in our sample for the years 1995 to 2014.

Demographics. We controlled for socio-demographic factors, which previous studies had shown to be related to propensity to donate (see Piersma et al. (2017) for a recent review on determinants of blood donation). We included (a) age (as our dependent variable is dependent on years lived), (b) gender (male/female), (c) education (age when stopped full-time education), (d) partner status (living with partner: yes/no), (e) employment status (employed: yes/no), (f) parental status (operationalized as children in household: yes/no), and (g) type of community (three levels: large town; small/middle-sized town; rural area). 


\section{Matching country-level indicators by year}

All three country-level variables of public trust and healthcare quality (which are available for multiple years) were matched to respondents from the Eurobarometer by year. That is, we selected the indicator value that is closest to the assumed time point when the respondent has donated blood. As we did not know when exactly respondents donated blood, we took as an approximation the average time point within the age range that respondents are eligible to donate (in most European countries the permitted age range for blood donation is $18-65$ years). The estimated donation_timepoint $t_{r}$ was calculated in the following manner:

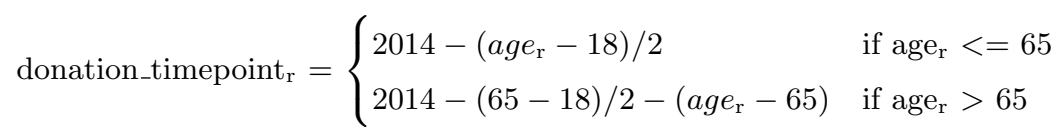

Here donation_timepoint $\mathrm{r}_{\mathrm{r}}$ is the assumed time point of donation(s) of respondent $\mathrm{r}$; 2014 is the time of the survey; age $_{\mathrm{r}}$ is the age of respondent $\mathrm{r}$ at that time; 18 is the minimum and 65 is the maximum age for blood donation in most European countries. As an example, a respondent who is 22 years old at the time of the study has a donation_timepoint of 2012; a respondent who is 48 years old has a donation_timepoint of 1999; and a respondent who is 80 years old has a donation_timepoint of 1975.5.

\section{Statistical analyses}

Exclusions. Respondents younger than 18 years were excluded since most EU countries do not permit people under 18 to donate blood.

Multilevel modeling. We employed multilevel logistic mixed models for all main analyses, where individuals were nested in countries. The models included individuallevel sociodemographic variables and country-level variables (i.e., healthcare quality and public trust) as fixed effects, as well as allowing the intercept to vary by country and by indicator survey wave. The estimation technique is maximum likelihood. All tests are two-sided. Missing values were handled by list-wise deletion.

We first test for the significance of the random components (country and survey wave) of the baseline model by performing log-likelihood-ratio tests of models with and without constrained variance. Then we add the individual-level socio-demographic variables to the model, and finally run models with the country-level predictors. The limited number of countries in our sample $(\mathrm{k}=28)$ constrained the number of countrylevel predictors that could be included in the model simultaneously (Bryan and Jenkins, 2016). Hence we implemented two separate models for (a) public trust and (b) healthcare quality (including HAQ index and healthcare expenditures). Prediction intervals are based on fixed coefficients and observation-level errors. All analyses were run with $\mathrm{R}$ version 4.0.2 using the packages lme4 (modeling), merTools (predictions), tidyverse (data transformation; plotting) and rnaturalearth (maps) (Bates et al., 2007; Knowles et al., 2016; South, 2017; Wickham et al., 2019).

Robustness checks and additional analyses. In order to test for the robustness of our findings, we performed multiple checks. First, we checked the robustness of results when running a full model including all three country-level indicators. To 
better interpret the results of this model, we tested for multicollinearity by checking if there is a relationship between country-level quality of healthcare and public trust in the healthcare system. Next, we examined whether the results were driven by any single country. To this end we excluded one of the 28 countries in each model specification. Lastly, we tested whether temporal discrepancy (i.e., uncertainty regarding the donation time point and resulting uncertainty regarding whether the country-level indicators capture the situation at the time the respondent donated) affected the reliability of our results. To examine this, we ran an additional analysis on the subset of respondents who are relatively young. If these individuals have donated, they will have done this relatively recently. For these respondents we can be more certain that the country-level indicators capture the state of quality of healthcare and public trust at the time of donation. We constructed this subset by taking the youngest respondents such that country level sample sizes amounted to at least $\mathrm{N}=250$.

\section{Results}

\section{Sample descriptives and country-level indicators over time}

Overall, 38.4\% ( $\mathrm{n}=10195)$ of all respondents had ever donated blood. Mean levels of blood donation at the country-level ranged from $22.8 \%$ of respondents from Portugal having ever donated blood to $52.9 \%$ of respondents from France having donated blood (see Fig. S1). Table 1 gives an overview of descriptive statistics of our sample. Table 2 provides indicator values for each country.

We found significant variation in all three country-level indicators across countries (see Fig. 2; trust in the healthcare system: $\mathrm{X}^{2}(27)=7434, \mathrm{p}<0.001$; HAQ index:

Table 1: Descriptive statistics for the dependent and independent variables (see section 2 for detailed description of variable derivation and theoretical range).

\begin{tabular}{llllll}
\hline \hline & Variable & Range & Mean & Std. & N \\
\hline Individual- & Blood donation & $0 ; 1$ & 0.38 & & 26,532 \\
level & Gender (female $=1)$ & $0 ; 1$ & 0.56 & & 26,532 \\
& Age (years) & $18 ; 99$ & 51.29 & 17.81 & 26,532 \\
& Education & $0 ; 89$ & 19.24 & 5.53 & 26,075 \\
& Living with partner & $0 ; 1$ & 0.65 & & 26,476 \\
& Employed & $0 ; 1$ & 0.49 & 26,532 \\
& Children in household & $0 ; 1$ & 0.19 & & 26,527 \\
& Type of community & & & & \\
& $\quad$ Large town (ref.) & $0 ; 1$ & 0.27 & & 26,518 \\
& $\quad$ Mid-sized town & $0 ; 1$ & 0.42 & & 26,518 \\
& $\quad$ Rural area & $0 ; 1$ & 0.31 & & 26,518 \\
\hline Country- & Trust in healthcare system & $1.84 ; 3.23$ & 2.61 & 0.31 & 26,532 \\
level & HAQ index & $58.3 ; 90.5$ & 75.56 & 6.93 & 26,532 \\
& Healthcare expenditures & $3.21 ; 11.97$ & 7.52 & 1.64 & 26,532 \\
\hline \hline
\end{tabular}

Sources: Eurobarometer (European Commission, 2018); European Values Survey (EVS, 2021); Healthcare access and quality index (Global Burden of Diseases Collaborative; Fullman et al., 2018); World Health Organization Global Health Expenditure database (World Health Organization, 2015). 
Table 2: Descriptives of indicators at the country-level, averaged across available years. All countries have data available for all years, except Cyprus for public trust in 1999.

\begin{tabular}{|c|c|c|c|c|c|c|}
\hline \multirow[t]{2}{*}{ Country } & \multicolumn{2}{|c|}{$\begin{array}{c}\text { Trust in the } \\
\text { healthcare } \\
\text { system }\end{array}$} & \multicolumn{2}{|c|}{ HAQ index } & \multicolumn{2}{|c|}{$\begin{array}{l}\text { Healthcare } \\
\text { expenditures }\end{array}$} \\
\hline & Mean & Std. & Mean & Std. & Mean & Std. \\
\hline Austria & 3.06 & 0.12 & 79.64 & 4.60 & 10.03 & 0.56 \\
\hline Belgium & 3.06 & 0.10 & 79.69 & 4.19 & 8.28 & 0.95 \\
\hline Bulgaria & 2.10 & 0.16 & 64.79 & 2.10 & 5.71 & 1.16 \\
\hline Croatia & 2.33 & 0.02 & 73.99 & 4.13 & 7.08 & 0.59 \\
\hline Cyprus & 2.66 & 0.00 & 76.23 & 4.16 & 5.68 & 0.96 \\
\hline Czech Republic & 2.41 & 0.05 & 75.99 & 5.20 & 6.81 & 0.37 \\
\hline Denmark & 2.80 & 0.04 & 78.63 & 2.61 & 8.74 & 0.95 \\
\hline Estonia & 2.62 & 0.07 & 68.08 & 4.85 & 6.02 & 0.55 \\
\hline Finland & 2.97 & 0.10 & 79.49 & 4.53 & 8.00 & 0.53 \\
\hline France & 2.91 & 0.01 & 78.75 & 4.57 & 10.29 & 0.42 \\
\hline Germany & 2.49 & 0.17 & 78.26 & 4.70 & 9.97 & 0.59 \\
\hline Greece & 2.09 & 0.11 & 81.19 & 3.40 & 8.50 & 0.56 \\
\hline Hungary & 2.24 & 0.05 & 69.40 & 4.47 & 7.40 & 0.37 \\
\hline Ireland & 2.48 & 0.27 & 80.15 & 3.95 & 6.94 & 0.83 \\
\hline Italy & 2.35 & 0.12 & 81.57 & 4.15 & 7.88 & 0.79 \\
\hline Latvia & 2.62 & 0.11 & 69.52 & 4.17 & 6.20 & 0.37 \\
\hline Lithuania & 2.23 & 0.02 & 68.45 & 3.27 & 5.86 & 0.59 \\
\hline Luxembourg & 3.03 & 0.12 & 80.94 & 4.63 & 6.63 & 1.09 \\
\hline Malta & 3.18 & 0.03 & 77.78 & 3.21 & 6.77 & 1.41 \\
\hline Netherlands & 2.88 & 0.05 & 81.75 & 2.98 & 8.01 & 0.99 \\
\hline Poland & 2.54 & 0.16 & 69.59 & 5.68 & 5.93 & 0.54 \\
\hline Portugal & 2.38 & 0.09 & 74.00 & 5.90 & 8.47 & 1.13 \\
\hline Romania & 2.62 & 0.06 & 63.69 & 5.05 & 4.21 & 0.99 \\
\hline Slovakia & 2.49 & 0.03 & 69.97 & 3.09 & 6.45 & 0.88 \\
\hline Slovenia & 2.79 & 0.05 & 75.10 & 4.86 & 7.91 & 0.61 \\
\hline Spain & 2.80 & 0.11 & 79.91 & 5.20 & 7.83 & 0.70 \\
\hline Sweden & 2.88 & 0.01 & 83.47 & 3.12 & 8.44 & 0.81 \\
\hline United Kingdom & 2.76 & 0.18 & 77.79 & 3.40 & 7.45 & 1.05 \\
\hline
\end{tabular}

Sources: European Values Survey (EVS, 2021, available years: 1999, 2008); Healthcare access and quality index (Global Burden of Diseases Collaborative; Fullman et al., 2018, available years: 1990, 1995, 2000, 2005, 2010, 2015); World Health Organization Global Health Expenditure database (World Health Organization, 2015, available years: 19952014).

$\mathrm{X}^{2}(27)=429.51, \mathrm{p}<0.001$; healthcare expenditures: $\left.\mathrm{X}^{2}(27)=78.71, \mathrm{p}<0.001\right)$. Notably, levels of trust in the healthcare system and healthcare quality were relatively high across all countries, which is not surprising given that most European countries are industrialized countries. However, there was also variation in public trust, such that trust appeared to be higher in Western and Northern European countries compared to Eastern and Southern European countries (see Fig. 1A). Both healthcare quality 


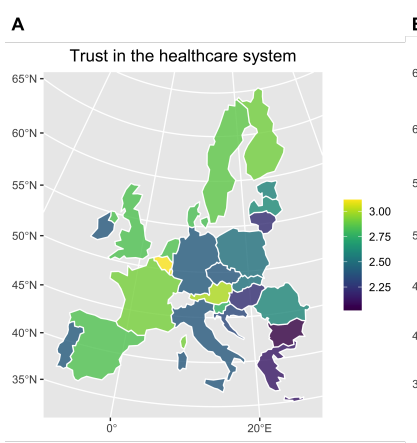

B

HAQ index
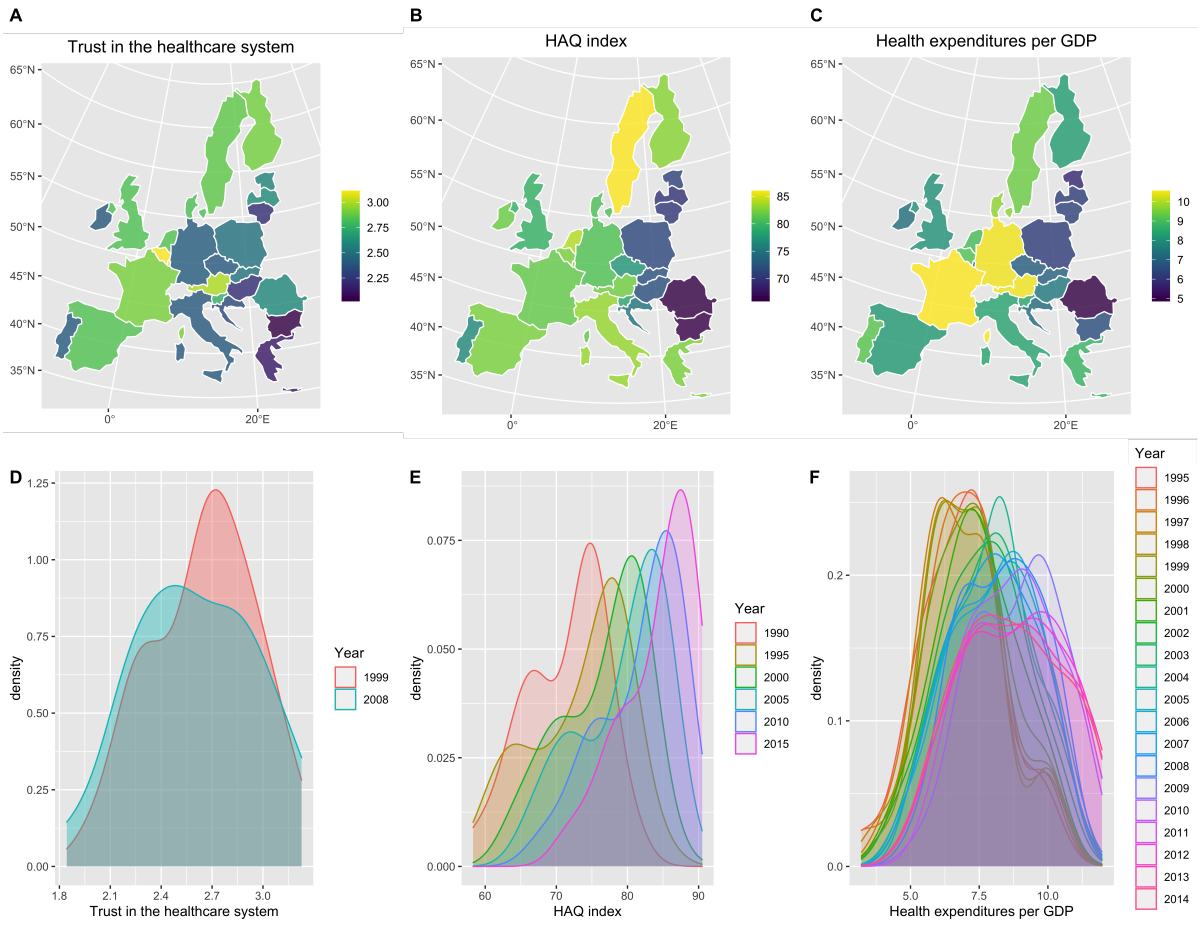

Figure 1: Distribution of country-level indicators across countries and over time. First row: Maps displaying (A) trust in the healthcare system, (B) healthcare quality as measured by the HAQ index and (C) healthcare quality as measured by healthcare expenditures per GDP. Second row: Density plots displaying (D) trust in the healthcare system, (E) healthcare quality as measured by the HAQ index and (F) healthcare quality as measured by healthcare expenditures per GDP.

indicators also exhibited a divide between Eastern and Western Europe, such that healthcare quality tended to be lower in Eastern than in Western European countries (see Fig. 1B and 1C). The appendix provides further maps depicting indicator variation across countries for different time points (Fig. S2 - S4).

Not only was there variation of country-level indicators across countries, but indicators also varied across time. More specifically, public trust overall decreased over time (Fig. 1D), whereas healthcare quality both in terms of the HAQ index and healthcare expenditures increased (Fig. 1E and $1 \mathrm{~F}$ ). Indeed, the positive correlations between survey time point and the two healthcare quality indicators were strong (HAQ index: Pearson's $\mathrm{r}=0.99, \mathrm{p}<0.001$; healthcare expenditures: Pearson's $\mathrm{r}=0.97, \mathrm{p}<0.001$ ). When examining trends over time at the country-level, we find that trust in the healthcare system decreased between 1999 and 2008 in most countries (i.e., there is a decrease in public trust in 17 out of 28 countries, see Fig. S5). HAQ index continuously increases over time for all countries (except for the baltic states Lithuania, Estonia, and Latvia between 1990 and 1995; Fig. S6). For the annual data on healthcare expenditures per GDP there is greater fluctuation across years (see Fig. S7), but overall all countries exhibit mild to strong increases in healthcare expenditures across time (see Fig. S8). 


\section{Main results}

As hypothesized, we found a positive main effect of trust in the healthcare system on blood donation propensity ( $\mathrm{b}=0.114, \mathrm{p}<0.001$; Model 2 in Table S2). However, neither measure of healthcare quality was statistically significantly associated with blood donation behavior (HAQ: $\mathrm{b}=0.101, \mathrm{p}=0.07$; healthcare expenditures: $\mathrm{b}=-0.020$, $\mathrm{p}=0.628$; Model 3 in Table S2). A visualization of the model results is presented in Fig. 2, which plots the predictive margins of donating blood for a representative European woman against different levels of public trust (Fig. 2A), HAQ index (Fig. 2B), and healthcare expenditures (Fig. 2C). As illustrated in Fig. 2A, the results indicate that respondents from countries where trust in the healthcare system is high are more likely to have donated blood. The association between blood donation behavior and healthcare quality measured by the HAQ index is also positive (Fig. 2B), albeit with higher uncertainty around the estimate (as also indicated by a lack of statistical significance in the model). Lastly, the likelihood of having donated was not higher for individuals residing in countries with higher healthcare expenditures per GDP (Fig. $2 \mathrm{C})$ compared to those living in countries with lower healthcare expenditures.
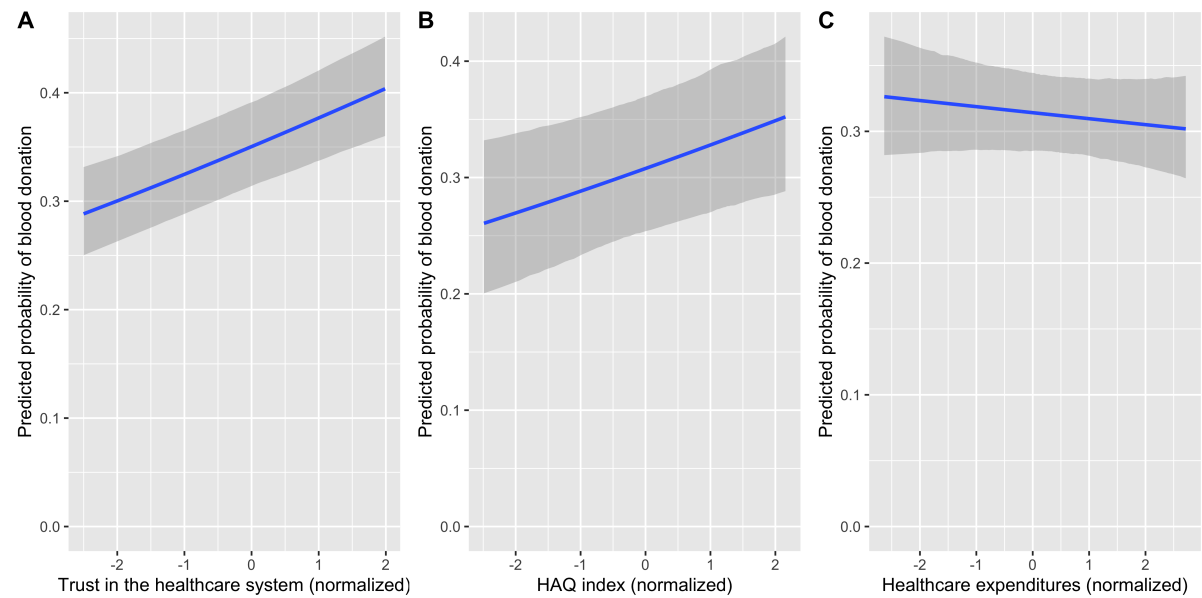

Figure 2: Predictive margins of donating blood for a representative European woman (i.e., mean-aged, living with a partner without children in a small town, employed, and having completed full-time education at age 19) as a function of (A) trust in the healthcare system, (B) healthcare quality as measured by the HAQ index and (C) healthcare quality as measured by healthcare expenditures per GDP. Prediction bands indicate $80 \%$ prediction intervals.

Lastly, model 1 revealed that several individual-level socio-demographic variables are associated with blood donation behavior, largely in line with previous studies (e.g., Piersma et al. (2017)). In particular, older, male, employed and more educated individuals, and those living with a partner were more likely to have donated blood during their lifetime (see Table S2 for an overview).

\section{Additional results}

All models included random intercepts for country, which a log-likelihood test comparing the intercept-only model with and without random intercepts confirmed to be justified $\left(\chi^{2}(1)=501.79, \mathrm{p}<0.001\right)$. Moreover, intercepts were allowed to vary 
by survey wave, which also proved to be justified by log-likelihood tests (wave trust $_{\text {: }}$ : $\chi^{2}(1)=144.6, \mathrm{p}<0.001$; wave $_{\mathrm{HAQ}}: \chi^{2}(1)=214.33, \mathrm{p}<0.001$; wave $_{\text {expenditures }}: \chi^{2}(1)=$ 183.07, $\mathrm{p}<0.001)$. Including survey wave random effects is particularly important for two reasons: Firstly, our dependent variable is dependent on time (i.e., we measure blood donation during the lifetime, which results in older individuals being more likely to have donated blood) and secondly, the country-level indicators vary systematically over time (i.e., public trust decreased, but healthcare quality increased over time). Hence, not accounting for survey wave could lead to spurious effects driven by older individuals being more likely to have donated blood, but having donated during a time when public trust was higher and healthcare quality was lower compared to the time when younger individuals donated. In accordance with this reasoning, an additional model without survey wave random effects (see Table S2, Model 5) showed that public trust is positively associated with donating blood, while the HAQ index and healthcare expenditures are negatively associated with donation behavior. These negative effects of HAQ index and healthcare expenditures can be explained by systematic temporal variation. Indeed, this interpretation is also in line with the descriptive results, which illustrate that public trust, HAQ index and healthcare expenditures are all positively related to country-level mean levels of blood donation (Fig. S9).

Moreover, we also implemented one full model which included all three countrylevel indicators. The results of this analysis mirrored the results of the separate models for public trust and healthcare quality. While trust in the healthcare system had a significant positive effect on blood donation behavior $(b=0.120, p<0.001$; Model 4 in Table S2), HAQ index and healthcare expenditures were not statistically significantly associated with having donated blood (HAQ: $\mathrm{b}=0.083, \mathrm{p}=0.154$; healthcare expenditures: $\mathrm{b}=-0.051, \mathrm{p}=0.226$; Model 4 in Table S2). However, we also found that our country-level indicators are correlated, which raises issues of multicollinearity in the full model. More specifically, public trust and HAQ index were significantly correlated (Pearson's $\mathrm{r}=0.48, \mathrm{p}<0.05$ ), and HAQ index and healthcare expenditures were also strongly correlated (Pearson's $\mathrm{r}=0.69, \mathrm{p}<0.001$ ). Public trust and healthcare expenditures were not significantly correlated (Pearson's $r=0.29, \mathrm{p}=0.137$ ). Given the strong correlation between HAQ index and healthcare expenditures, we implemented an additional robustness check in which separate models were run for HAQ index and healthcare expenditures. The results of these two models were similar to the results reported for the combined model (HAQ: $\mathrm{b}=0.094, \mathrm{p}=0.088$; healthcare expenditures: $\mathrm{b}=-0.021, \mathrm{p}=0.609)$.

We also conducted additional robustness checks in which we excluded one of the 28 countries in each specification. Our main results remained robust for trust in the healthcare system and healthcare expenditures. However, in six specifications there was now a significant positive effect of HAQ index (see Table S3; excluded countries: Italy, Latvia, Lithuania, Malta, Slovenia, or Sweden). That is, excluding one of these six countries had as a result that higher healthcare quality in terms of HAQ index was associated with a higher likelihood to have donated blood.

Lastly, we conducted a robustness check on exclusively young respondents by including only respondents 43 years or younger. This cutoff resulted in all country-level sample sizes being larger than 250 (except for three small countries: Malta $(\mathrm{n}=149)$, Cyprus $(\mathrm{n}=183)$ and Luxembourg $(\mathrm{n}=187))$. Models were hence run on $\mathrm{N}_{\text {young }}$ $=9421$, which corresponds to $36 \%$ of the original sample size. The summary statistics (see Table S4) illustrate that individuals in this subsample are less likely to have donated blood, more educated, more likely to be employed and have children in the 
household, and more likely to live in a city than in a rural area, compared to the full sample. Moreover, country-level trust in the healthcare system is lower, whereas HAQ index and healthcare expenditures are higher, in this subsample compared to the full sample. Despite these differences, the overall distribution of the three indicators across countries appears to be similar to the indicator distributions in the full sample (see Fig. S10). The models for this subsample however revealed no significant effect of trust in the healthcare system, HAQ index or healthcare expenditures on blood donation behavior (see Table S5). This indicates that the country-level indicators are not associated with donating blood when examining a smaller subsample of young respondents.

\section{Discussion}

In this paper we investigated the relationship between blood donation, public trust in the healthcare system and healthcare quality. As predicted, we found a positive association between public trust in the healthcare system and blood donation: the higher trust is in a country, the higher an individual's probability of having donated blood. However, neither measure of objective healthcare quality was statistically significantly related to blood donation behavior. While the three country-level indicators of public trust and healthcare quality exhibited similar spatial distributions across countries, we found an interesting pattern in the distribution of indicators over time. That is, trust in the healthcare system decreased between 1999 and 2008, whereas healthcare quality increased between 1990 and 2015 for most countries.

In addition to our main results, we also gained further insights from several robustness checks. Firstly, these analyses provided some evidence that healthcare quality in terms of HAQ index may after all be associated with blood donation behavior. That is, in six model specifications that excluded respondents from Italy, Latvia, Lithuania, Malta, Slovenia, or Sweden, respectively, there was actually a statistically significant positive effect of HAQ index on propensity to donate blood. Given that the HAQ index does not reach significance in our main model, we interpret this as mixed evidence for a relationship between HAQ index and blood donation. Secondly, the models only including the subset of young respondents indicated that none of the three country-level indicators predicted blood donation. The null effect of public trust was particularly unexpected given the main model results. A possible explanation for this may be that the sample size was greatly reduced in these models and that young respondents were overall less likely to have donated blood.

Our findings shed new light on how perceptions and objective characteristics of the healthcare system relates to blood donation behavior, but several open questions remain for future research to explore. Even though we found that a relatively simple measure of trust in the healthcare system predicts blood donation behavior, a more fine-grained measure of public trust would aid in further understanding the results (see for example Ghoshal et al. (2021)). In particular, our measure of trust potentially captures different related concepts, such as trust in the healthcare system as a whole, trust in health institutions (e.g., hospitals), as well as trust in healthcare professionals (e.g., physicians; van Der Schee et al. (2007)). Our results cannot distinguish between these different targets of trust. Related to this issue, independent blood banks may not be perceived as part of the healthcare system in all countries, since European countries vary in their blood collection systems and in some countries blood banks operate relatively independently (Healy, 2000). Moreover, this investigation was limited by 
the number of countries $(\mathrm{k}=28)$ included in the Eurobarometer survey. Although additionally including country-level indicators such as GDP and average level of education would be interesting, the limited number of countries in our sample restricted the number of country-level variables we could include in the models (Bryan and Jenkins, 2016). Lastly, our results remain inconclusive as to whether there is a relationship between healthcare quality (in terms of HAQ index) and blood donation. Healthcare quality may well matter for blood donation behavior, and further research including individuals from a larger set of countries would be helpful for illuminating this potential association.

Nonetheless, this study provides a novel perspective to understanding what drives people to donate blood and how the broader context in which donation takes place shapes behavior. Although many proximate factors (e.g., perceived risks from donation or efficiency of the donation procedure) have been explored in the previous literature, it has remained unclear whether and how more macro-level factors (e.g., public trust and healthcare quality) influence behavior, for example by affecting whether people think it is risky to donate. Our findings suggest that people's perceptions of the healthcare system, in particular public trust, do play a role for blood donation behavior. This again may offer clues about how blood banks, governments and other healthcare institutions can ensure a sufficient supply of blood. For example, these institutions could invest more in fostering trust in the healthcare system, by engaging in earnest messaging that signals dependability and trustworthiness. Here special attention should be given to communities with particularly low trust in the healthcare system, such as those with members of minority or religious groups, who are more likely to have experienced discrimination and to suffer from lack of representation within the healthcare system (Boulware et al., 2016; Musa et al., 2009).

Furthermore, our results highlight the importance of subjective factors, such as public trust, opposed to objective measures of healthcare quality, for blood donation behavior. This is in line with research emphasizing the key role of affective attitudes and beliefs for donating substances of human origin, such as blood (Conner et al., 2013; Farley and Stasson, 2003; Morgan et al., 2008). This uncoupling between the objective level of the healthcare quality and subjective trust in the healthcare system presents an intriguing puzzle in itself, which would benefit from further research. Relatedly, it remains an interesting topic for future studies to establish which factors influence public trust if not the objective performance of the healthcare system, and what their respective contribution is (e.g., to what extent debates in the public discourse affect public trust). A better understanding of these mechanisms would also aid in designing effective interventions for building and sustaining public trust in the healthcare system.

More broadly, our findings have important implications in light of what has been called a "Global Trust Crisis" (Algan et al., 2017). This crisis describes the concerning observation that trust in institutions, including trust in government and in science, has seen a decline across several decades (Citrin and Stoker, 2018; Mechanic, 1996; Hardin and Offe, 1999; Perry et al., 2021; Gauchat, 2012). Here we find that trust in the healthcare system also decreases between 1999 and 2008 for many countries in our sample. This is particularly surprising given the continuous increase in healthcare quality over time in virtually all European countries. Although medicine has historically been one of the most trusted institutions (Mechanic, 1996), the decrease of trust in the healthcare system observed here is also reflected in other domains, for instance in significant vaccine hesitancy during the current COVID-19 pandemic (Dror et al., 2020). This erosion of institutional trust has been warned to result in a decline in 
effectiveness of government and democratic stability (Citrin and Stoker, 2018). Indeed, a decline in trust in institutions is related to various negative societal outcomes, including lower political participation (Putnam, 2000) and higher unemployment rates (Algan et al., 2017). The current study adds to these consequences a potential threat to vital blood collection efforts. Without a sufficient supply of blood, heart surgery patients, victims of serious trauma, and chemotherapy patients will not be able to receive the medical care they urgently need. Hence, building and maintaining trust in the healthcare system should be a priority for governments and organizations in order to ensure a continuous supply of blood. More generally, it is important to recognize that (changes in) people's perception of the healthcare system, including public trust, can have significant ramifications on different kinds of behaviors that take place in these medical settings, such as blood donation. 


\section{Declaration of Competing Interest}

The authors declare that they have no competing interests.

\section{Funding}

This work was supported by the European Research Council (ERC) under the European Union's Horizon 2020 research and innovation program [grant agreement No. 802227 to E.-M.M.]. The position of P.W. as Visiting Stead Family Chair in International Philanthropy and Visiting Associate Professor of Philanthropic Studies is funded through a donation from Mary Joy and Jerre Stead to the Indiana University Lilly Family School of Philanthropy. P.W.'s position as Professor of Societal Significance of Charitable Lotteries at Vrije Universiteit Amsterdam is funded by the Postcode Lottery.

\section{Author Contributions}

All authors contributed to the design and analysis plan. C.G. performed analyses and wrote the initial draft of the paper. All authors contributed to the final paper.

\section{References}

Abbott, S. and Freeth, D. (2008). Social capital and health: starting to make sense of the role of generalized trust and reciprocity. Journal of Health Psychology, 13(7):874883.

Algan, Y., Guriev, S., Papaioannou, E., and Passari, E. (2017). The european trust crisis and the rise of populism. Brookings Papers on Economic Activity, 2017(2):309400 .

Bates, D., Sarkar, D., Bates, M. D., and Matrix, L. (2007). The lme4 package. $R$ package version, 2(1):74.

Boenigk, S., Mews, M., and de Kort, W. (2015). Missing minorities: explaining low migrant blood donation participation and developing recruitment tactics. VOLUNTAS: International Journal of Voluntary and Nonprofit Organizations, 26(4):1240-1260.

Boulware, L., Ratner, L., Ness, P., Cooper, L., Campbell-Lee, S., LaVeist, T., and Powe, N. (2002). The contribution of sociodemographic, medical, and attitudinal factors to blood donation among the general public. Transfusion, 42(6):669-678.

Boulware, L. E., Cooper, L. A., Ratner, L. E., LaVeist, T. A., and Powe, N. R. (2016). Race and trust in the health care system. Public Health Reports.

Bryan, M. L. and Jenkins, S. P. (2016). Multilevel modelling of country effects: A cautionary tale. European Sociological Review, 32(1):3-22.

Chen, L. (2017). Applying the extended theory of planned behaviour to predict chinese people's non-remunerated blood donation intention and behaviour: The roles of perceived risk and trust in blood collection agencies. Asian Journal of Social Psychology, 20(3-4):221-231. 
Citrin, J. and Stoker, L. (2018). Political trust in a cynical age. Annual Review of Political Science, 21:49-70.

Conner, M., Godin, G., Sheeran, P., and Germain, M. (2013). Some feelings are more important: Cognitive attitudes, affective attitudes, anticipated affect, and blood donation. Health Psychology, 32(3):264.

Cuevas, A. G., O'Brien, K., and Saha, S. (2019). Can patient-centered communication reduce the effects of medical mistrust on patients' decision making? Health Psychology, 38(4):325.

De Kort, W., Wagenmans, E., Van Dongen, A., Slotboom, Y., Hofstede, G., and Veldhuizen, I. (2010). Blood product collection and supply: a matter of money? Vox Sanguinis, 98(3p1):e201-e208.

Dror, A. A., Eisenbach, N., Taiber, S., Morozov, N. G., Mizrachi, M., Zigron, A., Srouji, S., and Sela, E. (2020). Vaccine hesitancy: the next challenge in the fight against covid-19. European Journal of Epidemiology, 35(8):775-779.

European Commission (2018). European Commission, Data from Eurobarometer 82.2. GESIS Data Archive for the Social Sciences. ZA5931 Datafile Version 3.0.0. Available at doi.org/10.4232/1.12999.

EVS (2021). EVS, EVS Trend File 1981-2017. GESIS Data Archive, Cologne. ZA7503 Data file Version 2.0.0. Available at doi:10.4232/1.13736.

Farley, S. D. and Stasson, M. F. (2003). Relative influences of affect and cognition on behavior: Are feelings more related to blood donation intentions? Experimental Psychology, 50(1):55.

Fullman, N., Yearwood, J., Abay, S. M., Abbafati, C., Abd-Allah, F., Abdela, J., Abdelalim, A., Abebe, Z., Abebo, T. A., Aboyans, V., et al. (2018). Measuring performance on the healthcare access and quality index for 195 countries and territories and selected subnational locations: a systematic analysis from the global burden of disease study 2016. The Lancet, 391(10136):2236-2271.

Gauchat, G. (2012). Politicization of science in the public sphere: A study of public trust in the united states, 1974 to 2010. American Sociological Review, 77(2):167187.

Ghoshal, A., O'Carroll, R. E., Ferguson, E., Shepherd, L., Doherty, S., Mathew, M., Morgan, K., and Doyle, F. (2021). Assessing medical mistrust in organ donation across countries using item response theory. Journal of Health Psychology.

Giles, M., Mcclenahan, C., Cairns, E., and Mallet, J. (2004). An application of the theory of planned behaviour to blood donation: the importance of self-efficacy. Health Education Research, 19(4):380-391.

Gille, F., Smith, S., and Mays, N. (2015). Why public trust in health care systems matters and deserves greater research attention. Journal of Health Services Research ES Policy, 20(1):62-64.

Gille, F., Smith, S., and Mays, N. (2017). Towards a broader conceptualisation of 'public trust'in the health care system. Social Theory \& Health, 15(1):25-43.

Gillum, R. F. and Masters, K. S. (2010). Religiousness and blood donation: findings from a national survey. Journal of Health Psychology, 15(2):163-172. 
Gilson, L. (2003). Trust and the development of health care as a social institution. Social Science $\& 3$ Medicine, 56(7):1453-1468.

Gorleer, S., Bracke, P., and Hustinx, L. (2020). The organizational field of blood collection: A multilevel analysis of organizational determinants of blood donation in europe. European Sociological Review, 36(3):474-492.

Hardin, R. and Offe, C. (1999). Democracy and trust. Cambridge University Press.

Healy, K. (2000). Embedded altruism: blood collection regimes and the european union's donor population. American Journal of Sociology, 105(6):1633-1657.

Henrich, J., Heine, S. J., and Norenzayan, A. (2010). The weirdest people in the world? Behavioral and Brain Sciences, 33(2-3):61-83.

Hofstede, G. (2001). Culture's consequences: Comparing values, behaviors, institutions and organizations across nations. Sage publications.

Huis in 't Veld, E. M., de Kort, W. L., and Merz, E.-M. (2019). Determinants of blood donation willingness in the european union: a cross-country perspective on perceived transfusion safety, concerns, and incentives. Transfusion, 59(4):1273-1282.

Inglehart, R. (2000). Globalization and postmodern values. Washington Quarterly, $23(1): 215-228$.

Klinkenberg, E. F., Fransen, M. P., de Kort, W. L., van Weert, J. C., Huis, E. M., et al. (2021). Blood donation among individuals of african origin in the netherlands: how are barriers and motivators associated with intention? Blood Transfusion, 19(1):24.

Knowles, J. E., Frederick, C., and Knowles, M. J. E. (2016). Package 'mertools'.

Masser, B., Ferguson, E., Merz, E.-M., and Williams, L. (2020). Beyond description: The predictive role of affect, memory, and context in the decision to donate or not donate blood. Transfusion Medicine and Hemotherapy, 47(2):175-185.

Masser, B. M., White, K. M., Hamilton, K., and McKimmie, B. M. (2011). An examination of the predictors of blood donors' intentions to donate during two phases of an avian influenza outbreak. Transfusion, 51(3):548-557.

Masser, B. M., White, K. M., Hyde, M. K., and Terry, D. J. (2008). The psychology of blood donation: current research and future directions. Transfusion Medicine Reviews, 22(3):215-233.

Mechanic, D. (1996). Changing medical organization and the erosion of trust. The Milbank Quarterly, pages 171-189.

Merz, E.-M., Zijlstra, B. J., and De Kort, W. L. (2016). Perceived blood transfusion safety: a cross-european comparison. Vox Sanguinis, 110(3):258-265.

Merz, E.-M., Zijlstra, B. J., and De Kort, W. L. (2017). Blood donor show behaviour after an invitation to donate: The influence of collection site factors. Vox Sanguinis, 112(7):628-637.

Morgan, S. E., Stephenson, M. T., Harrison, T. R., Afifi, W. A., and Long, S. D. (2008). facts versus feelingshow rational is the decision to become an organ donor? Journal of Health Psychology, 13(5):644-658. 
Musa, D., Schulz, R., Harris, R., Silverman, M., and Thomas, S. B. (2009). Trust in the health care system and the use of preventive health services by older black and white adults. American Journal of Public Health, 99(7):1293-1299.

Perry, J. et al. (2021). Trust in public institutions: Trends and implications for economic security.

Piersma, T. W., Bekkers, R., Klinkenberg, E. F., De Kort, W. L., and Merz, E.-M. (2017). Individual, contextual and network characteristics of blood donors and nondonors: a systematic review of recent literature. Blood Transfusion, 15(5):382.

Pilgrim, D., Tomasini, F., and Vassilev, I. (2010). Examining trust in healthcare: A multidisciplinary perspective. Macmillan International Higher Education.

Putnam, R. D. (2000). Bowling alone: America's declining social capital. In Culture and politics, pages 223-234. Springer.

PytlikZillig, L. M. and Kimbrough, C. D. (2016). Consensus on conceptualizations and definitions of trust: Are we there yet? Interdisciplinary Perspectives on Trust, pages $17-47$.

Scherer, L. D., McPhetres, J., Pennycook, G., Kempe, A., Allen, L. A., Knoepke, C. E., Tate, C. E., and Matlock, D. D. (2021). Who is susceptible to online health misinformation? a test of four psychosocial hypotheses. Health Psychology.

South, A. (2017). Rnaturalearth: world map data from natural earth. $R$ package version 0.1.0.

Tison, G. H., Liu, C., Ren, F., Nelson, K., and Shan, H. (2007). Influences of general and traditional chinese beliefs on the decision to donate blood among employerorganized and volunteer donors in beijing, china. Transfusion, 47(10):1871-1879.

van Der Schee, E., Braun, B., Calnan, M., Schnee, M., and Groenewegen, P. P. (2007). Public trust in health care: a comparison of germany, the netherlands, and england and wales. Health Policy, 81(1):56-67.

Vergara, R. J. D., Sarmiento, P. J. D., and Lagman, J. D. N. (2021). Building public trust: a response to covid-19 vaccine hesitancy predicament. Journal of Public Health, 43(2):e291-e292.

Wickham, H., Averick, M., Bryan, J., Chang, W., McGowan, L. D., François, R., Grolemund, G., Hayes, A., Henry, L., Hester, J., et al. (2019). Welcome to the tidyverse. Journal of Open Source Software, 4(43):1686.

World Health Organization (2015). Global health expenditure database (ghed). 


\section{Appendix}

Table S 1: Dependent and independent variables employed in the analyses. $\triangleright$ denotes source: Eurobarometer; other sources in brackets.

\begin{tabular}{|c|c|c|c|}
\hline Variable & Description & Original item & Response range \\
\hline Blood donation & $\begin{array}{l}\text { Individual-level re- } \\
\text { sponse: Blood do- } \\
\text { nation during life- } \\
\text { time } \triangleright\end{array}$ & $\begin{array}{l}\text { During the lifetime of a person } \\
\text { it is possible to donate different } \\
\text { body substances (blood or cells) } \\
\text { to help other people. Could you } \\
\text { please indicate which ones you } \\
\text { have [...] donate[d] yourself? } \\
\text { Blood }\end{array}$ & $\begin{array}{l}0 ; 1 \text { (dummy coded) } \\
0 \text { (not donated blood in the } \\
\text { past) } \\
1 \text { (donated blood in the past) }\end{array}$ \\
\hline $\begin{array}{l}\text { Healthcare } \\
\text { quality }\end{array}$ & $\begin{array}{l}\text { Country-level vari- } \\
\text { able: Healthcare } \\
\text { expenditures per } \\
\text { GDP (in percent; } \\
\text { World Health Or- } \\
\text { ganization Global } \\
\text { Health Expendi- } \\
\text { ture database) }\end{array}$ & NA & $\begin{array}{l}\text { numeric (theoretical range: } 0-100 \\
\text { percent) }\end{array}$ \\
\hline & $\begin{array}{l}\text { Country-level vari- } \\
\text { able: Healthcare } \\
\text { Access and Qual- } \\
\text { ity Index (HAQ } \\
\text { index; Global } \\
\text { Burden of Diseases } \\
\text { Collaborative) }\end{array}$ & NA & $\begin{array}{l}\text { numeric (theoretical range: } 0 \text { - } \\
100)\end{array}$ \\
\hline
\end{tabular}

Public trust in the healthcare system
Country-level variable: Aggregated response of level of confidence in the healthcare system (European Values Survey)
How much confidence do you have $1.0-4.0$ in the healthcare system?

Aggregation of individual-level responses with response range:

1 (none at all)

2 (not very much)

3 (quite a lot)

4 (a great deal)

Controls Age of respondent How old are you?

numeric 
0 (Male)

1 (Female)

Education (Age
when finished full-
time education)
$\square$

Partner status (live with partner or not) $\triangleright$

Employment status $\triangleright$

\section{Parental status}

(operationalized

as children in

household) $\triangleright$

Type of community $\triangleright$
Could you give me the letter which corresponds best to your own current situation?

(recoded from 14 levels, e.g., married/remarried and living with/without children)

What is your current occupation?

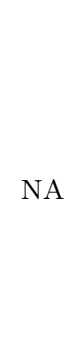

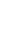
How old were you when you numeric
stopped full-time education?

\author{
$0 ; 1$ (dummy coded) \\ 0 (Living without partner)
}

1 (Living with partner)

$0 ; 1$ (dummy coded)

0 (unemployed)

1 (employed)

$0 ; 1$ (dummy coded)

0 (Living without children)

1 (Living with children)

$0 ; 1 ; 2$ (dummy coded)

0 (large town)

1 (small or middle sized town)

2 (rural area or village) 
Table S 2: Full multilevel model results.

\begin{tabular}{|c|c|c|c|c|c|c|}
\hline & & \multicolumn{3}{|c|}{ Main models } & \multicolumn{2}{|c|}{ Additional models } \\
\hline & & $(1)$ & $(2)$ & $(3)$ & $(4)$ & $(5)$ \\
\hline \multirow[t]{12}{*}{$\begin{array}{l}\text { Individual- } \\
\text { level }\end{array}$} & (Intercept) & $\begin{array}{c}-0.439^{* * *} \\
(0.069)\end{array}$ & $\begin{array}{c}-0.478^{* * *} \\
(0.137)\end{array}$ & $\begin{array}{c}-0.615^{* * *} \\
(0.221)\end{array}$ & $\begin{array}{c}-0.611^{* * *} \\
(0.205)\end{array}$ & $\begin{array}{c}-0.438^{* * *} \\
(0.080)\end{array}$ \\
\hline & Age (years) $\triangleright$ & $\begin{array}{c}0.216^{* * *} \\
(0.016)\end{array}$ & $\begin{array}{c}0.094^{* * *} \\
(0.024)\end{array}$ & $\begin{array}{c}-0.113^{*} \\
(0.060)\end{array}$ & $\begin{array}{c}-0.109^{*} \\
(0.060)\end{array}$ & $\begin{array}{l}0.097^{* * *} \\
(0.033)\end{array}$ \\
\hline & Gender $($ female $=1)$ & $\begin{array}{c}-0.449^{* * *} \\
(0.027)\end{array}$ & $\begin{array}{c}-0.456^{* * *} \\
(0.027)\end{array}$ & $\begin{array}{c}-0.464^{* * *} \\
(0.027)\end{array}$ & $\begin{array}{c}-0.464^{* * *} \\
(0.027)\end{array}$ & $\begin{array}{c}-0.452^{* * *} \\
(0.027)\end{array}$ \\
\hline & Education $\triangleright$ & $\begin{array}{c}0.182^{* * *} \\
(0.015)\end{array}$ & $\begin{array}{c}0.178^{* * *} \\
(0.015)\end{array}$ & $\begin{array}{c}0.174^{* * *} \\
(0.015)\end{array}$ & $\begin{array}{c}0.172^{* * *} \\
(0.015)\end{array}$ & $\begin{array}{l}0.179^{* * *} \\
(0.015)\end{array}$ \\
\hline & Living with partner & $\begin{array}{c}0.111^{* * *} \\
(0.029)\end{array}$ & $\begin{array}{c}0.092^{* * *} \\
(0.029)\end{array}$ & $\begin{array}{l}0.059^{* *} \\
(0.030)\end{array}$ & $\begin{array}{l}0.062^{* *} \\
(0.030)\end{array}$ & $\begin{array}{l}0.095^{* * *} \\
(0.029)\end{array}$ \\
\hline & Employed & $\begin{array}{c}0.299^{* * *} \\
(0.030)\end{array}$ & $\begin{array}{c}0.251^{* * *} \\
(0.031)\end{array}$ & $\begin{array}{c}0.218^{* * *} \\
(0.034)\end{array}$ & $\begin{array}{c}0.219^{* * *} \\
(0.034)\end{array}$ & $\begin{array}{l}0.280^{* * *} \\
(0.030)\end{array}$ \\
\hline & Children in household & $\begin{array}{c}0.035 \\
(0.037)\end{array}$ & $\begin{array}{l}0.087^{* *} \\
(0.038)\end{array}$ & $\begin{array}{l}0.082^{* *} \\
(0.041)\end{array}$ & $\begin{array}{l}0.084^{* *} \\
(0.041)\end{array}$ & $\begin{array}{c}0.055 \\
(0.038)\end{array}$ \\
\hline & Type of community & & & & & \\
\hline & Large town (ref.) & - & - & - & - & - \\
\hline & & - & - & - & - & - \\
\hline & Mid-sized town & $\begin{array}{l}-0.023 \\
(0.033)\end{array}$ & $\begin{array}{l}-0.027 \\
(0.033)\end{array}$ & $\begin{array}{l}-0.027 \\
(0.033)\end{array}$ & $\begin{array}{l}-0.029 \\
(0.033)\end{array}$ & $\begin{array}{l}-0.024 \\
(0.033)\end{array}$ \\
\hline & Rural area & $\begin{array}{l}-0.054 \\
(0.035)\end{array}$ & $\begin{array}{c}-0.061^{*} \\
(0.035)\end{array}$ & $\begin{array}{c}-0.064^{*} \\
(0.035)\end{array}$ & $\begin{array}{c}-0.066^{*} \\
(0.035)\end{array}$ & $\begin{array}{c}-0.059^{*} \\
(0.035)\end{array}$ \\
\hline \multirow[t]{6}{*}{$\begin{array}{l}\text { Country- } \\
\text { level }\end{array}$} & Trust in healthcare system $\triangleright$ & & $\begin{array}{c}0.114^{* * *} \\
(0.033)\end{array}$ & & $\begin{array}{c}0.120^{* * *} \\
(0.035)\end{array}$ & $\begin{array}{l}0.165^{* * *} \\
(0.034)\end{array}$ \\
\hline & HAQ index $\triangleright$ & & & $\begin{array}{l}0.101^{*} \\
(0.056)\end{array}$ & $\begin{array}{c}0.083 \\
(0.058)\end{array}$ & $\begin{array}{c}-0.114^{* *} \\
(0.048)\end{array}$ \\
\hline & Healthcare expenditures $\triangleright$ & & & $\begin{array}{l}-0.020 \\
(0.041)\end{array}$ & $\begin{array}{l}-0.051 \\
(0.042)\end{array}$ & $\begin{array}{c}-0.124^{* * *} \\
(0.041)\end{array}$ \\
\hline & Country random intercept & Yes & Yes & Yes & Yes & Yes \\
\hline & Survey wave random intercept & Yes & Yes & Yes & Yes & No \\
\hline & Observations & 26,019 & 26,019 & 26,019 & 26,019 & 26,019 \\
\hline
\end{tabular}

Note: Standard errors in brackets; *** denotes $\mathrm{p}<0.001$; ** denotes $\mathrm{p}<0.01$; ${ }^{*}$ denotes $\mathrm{p}<0.05 ; \triangleright$ indicates variable was normalized. Dependent variable is blood donation. All models control for sociodemographic factors. Main model M2 further includes trust in the healthcare system; M3 includes the two healthcare quality indicators. Additional models M4-M5 include trust in the healthcare system and the two healthcare quality indicators simultaneously. M4 includes survey wave random effects, whereas M5 does not. 
Table S 3: Coefficients of HAQ index for model specifications excluding individual countries (only specifications where HAQ index had a significant effect on blood donation are listed). Standard errors in brackets; ${ }^{*}$ denotes $\mathrm{p}<0.05$.

\begin{tabular}{lc}
\hline \hline Excluded country & HAQ index \\
\hline Italy & $0.112^{*}$ \\
& $(0.056)$ \\
Latvia & $0.121^{*}$ \\
& $(0.059)$ \\
Lithuania & $0.135^{*}$ \\
& $(0.060)$ \\
Malta & $0.126^{*}$ \\
& $(0.058)$ \\
Slovenia & $0.116^{*}$ \\
& $(0.057)$ \\
Sweden & $0.126^{*}$ \\
& $(0.057)$ \\
\hline \hline
\end{tabular}

Table S 4: Descriptive statistics for the dependent and independent variables for the subsample of young respondents (age $<44$ ).

\begin{tabular}{llllll}
\hline \hline & Variable & Range & Mean & Std. & N \\
\hline Individual- & Blood donation & $0 ; 1$ & 0.34 & & 9640 \\
level & Gender (female $=1)$ & $0 ; 1$ & 0.56 & & 9640 \\
& Age (years) & $18 ; 43$ & 31.82 & 7.37 & 9640 \\
& Education & $0 ; 43$ & 20.26 & 4.14 & 9452 \\
& Living with partner & $0 ; 1$ & 0.65 & & 9609 \\
& Employed & $0 ; 1$ & 0.68 & & 9640 \\
& Children in household & $0 ; 1$ & 0.42 & & 9638 \\
& Type of community & & & & \\
& $\quad$ Large town (ref.) & $0 ; 1$ & 0.30 & & 9635 \\
& $\quad$ Mid-sized town & $0 ; 1$ & 0.42 & & 9635 \\
& $\quad$ Rural area & $0 ; 1$ & 0.28 & & 9635 \\
\hline Country- & Trust in healthcare system & $1.84 ; 3.23$ & 2.57 & 0.33 & 9640 \\
level & HAQ index & $64.2 ; 90.5$ & 79.91 & 6.07 & 9640 \\
& Healthcare expenditures & $4.57 ; 11.97$ & 8.19 & 1.62 & 9640 \\
\hline \hline
\end{tabular}

Sources: Eurobarometer (European Commission, 2018); European Values Survey (EVS, 2021); Healthcare access and quality index (Global Burden of Diseases Collaborative; Fullman et al., 2018); World Health Organization Global Health Expenditure database (World Health Organization, 2015). 
Table S 5: Model results for subsample of young respondents $($ age $<44)$.

\begin{tabular}{|c|c|c|c|}
\hline & & $(\mathrm{Y} 1)$ & $(\mathrm{Y} 2)$ \\
\hline \multirow[t]{12}{*}{$\begin{array}{l}\text { Individual- } \\
\text { level }\end{array}$} & (Intercept) & $\begin{array}{c}-0.411^{* * *} \\
(0.156)\end{array}$ & $\begin{array}{c}-0.341^{* *} \\
(0.159)\end{array}$ \\
\hline & Age (years) $\triangleright$ & $\begin{array}{c}0.360^{* * *} \\
(0.116)\end{array}$ & $\begin{array}{l}0.488^{* * *} \\
(0.107)\end{array}$ \\
\hline & Gender (female = 1) & $\begin{array}{c}-0.304^{* * *} \\
(0.046)\end{array}$ & $\begin{array}{c}-0.308^{* * *} \\
(0.046)\end{array}$ \\
\hline & Education $\triangleright$ & $\begin{array}{c}0.287^{* * *} \\
(0.032)\end{array}$ & $\begin{array}{c}0.281^{* * *} \\
(0.032)\end{array}$ \\
\hline & Living with partner & $\begin{array}{c}0.067 \\
(0.055)\end{array}$ & $\begin{array}{c}0.063 \\
(0.055)\end{array}$ \\
\hline & Employed & $\begin{array}{c}0.268^{* * *} \\
(0.055)\end{array}$ & $\begin{array}{c}0.256^{* * *} \\
(0.055)\end{array}$ \\
\hline & Children in household & $\begin{array}{c}0.067 \\
(0.053)\end{array}$ & $\begin{array}{c}0.081 \\
(0.051)\end{array}$ \\
\hline & Type of community & & \\
\hline & Large town (ref.) & - & - \\
\hline & & - & - \\
\hline & Mid-sized town & $\begin{array}{c}0.007 \\
(0.055)\end{array}$ & $\begin{array}{r}0.006 \\
(0.055)\end{array}$ \\
\hline & Rural area & $\begin{array}{l}-0.045 \\
(0.060)\end{array}$ & $\begin{array}{l}-0.045 \\
(0.060)\end{array}$ \\
\hline \multirow[t]{6}{*}{$\begin{array}{l}\text { Country- } \\
\text { level }\end{array}$} & Trust in healthcare system $\triangleright$ & $\begin{array}{c}0.025 \\
(0.047)\end{array}$ & \\
\hline & HAQ index $\triangleright$ & & $\begin{array}{c}0.062 \\
(0.090)\end{array}$ \\
\hline & Healthcare expenditures $\triangleright$ & & $\begin{array}{c}0.048 \\
(0.068)\end{array}$ \\
\hline & Country random intercept & Yes & Yes \\
\hline & Survey wave random intercept & Yes & Yes \\
\hline & Observations & 9,421 & 9,421 \\
\hline
\end{tabular}

Note: Standard errors in brackets; ${ }^{* * *}$ denotes $\mathrm{p}<0.001 ; * *$ denotes $\mathrm{p}<0.01$; * denotes $\mathrm{p}<0.05$; $\triangleright$ indicates variable was normalized. Dependent variable is blood donation. All models control for sociodemographic factors. Y1 further includes trust in the healthcare system; Y2 includes the two healthcare quality indicators. 


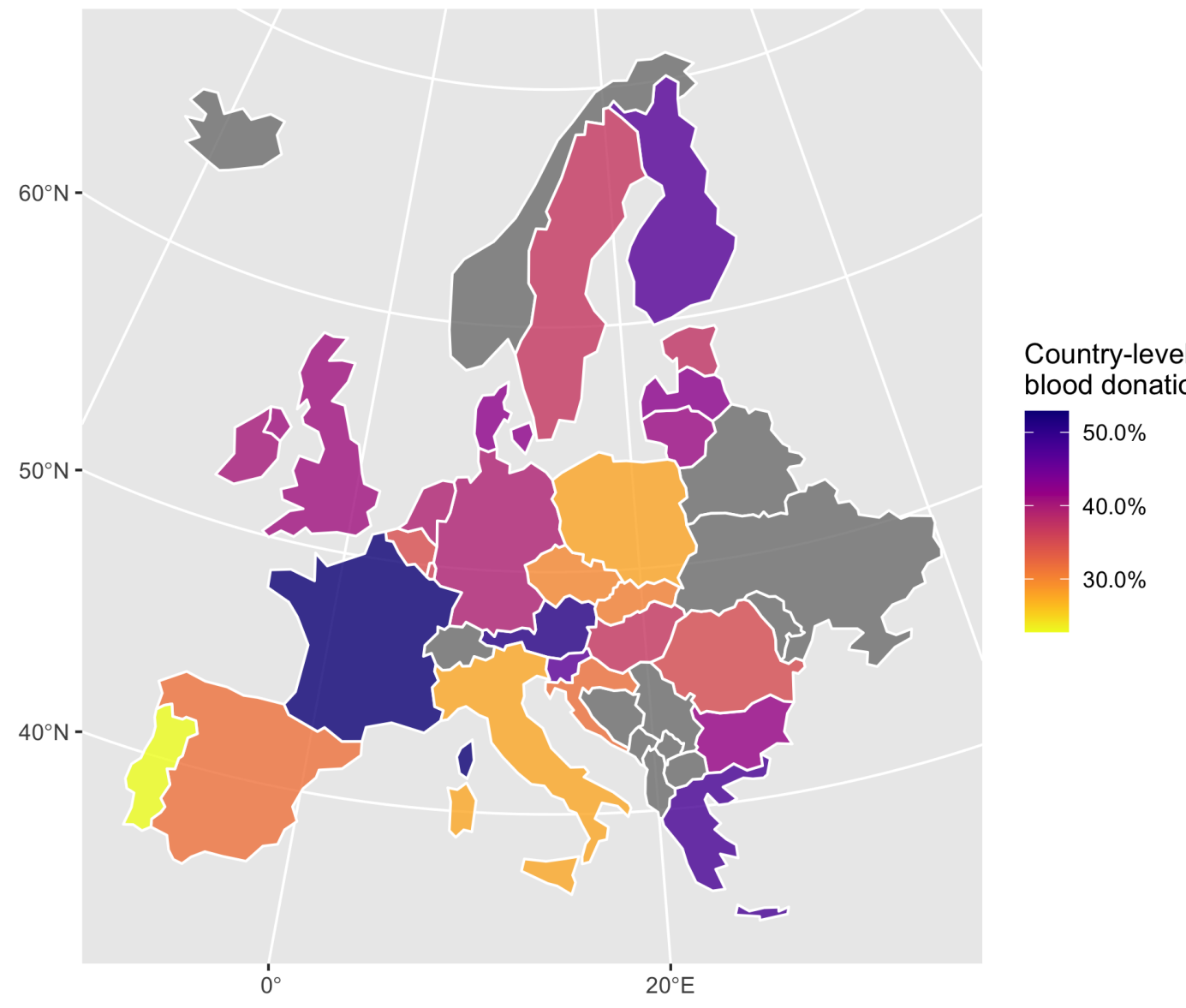

Figure S 1: Map of the proportion of individuals within a country who have donated blood (in percent). 


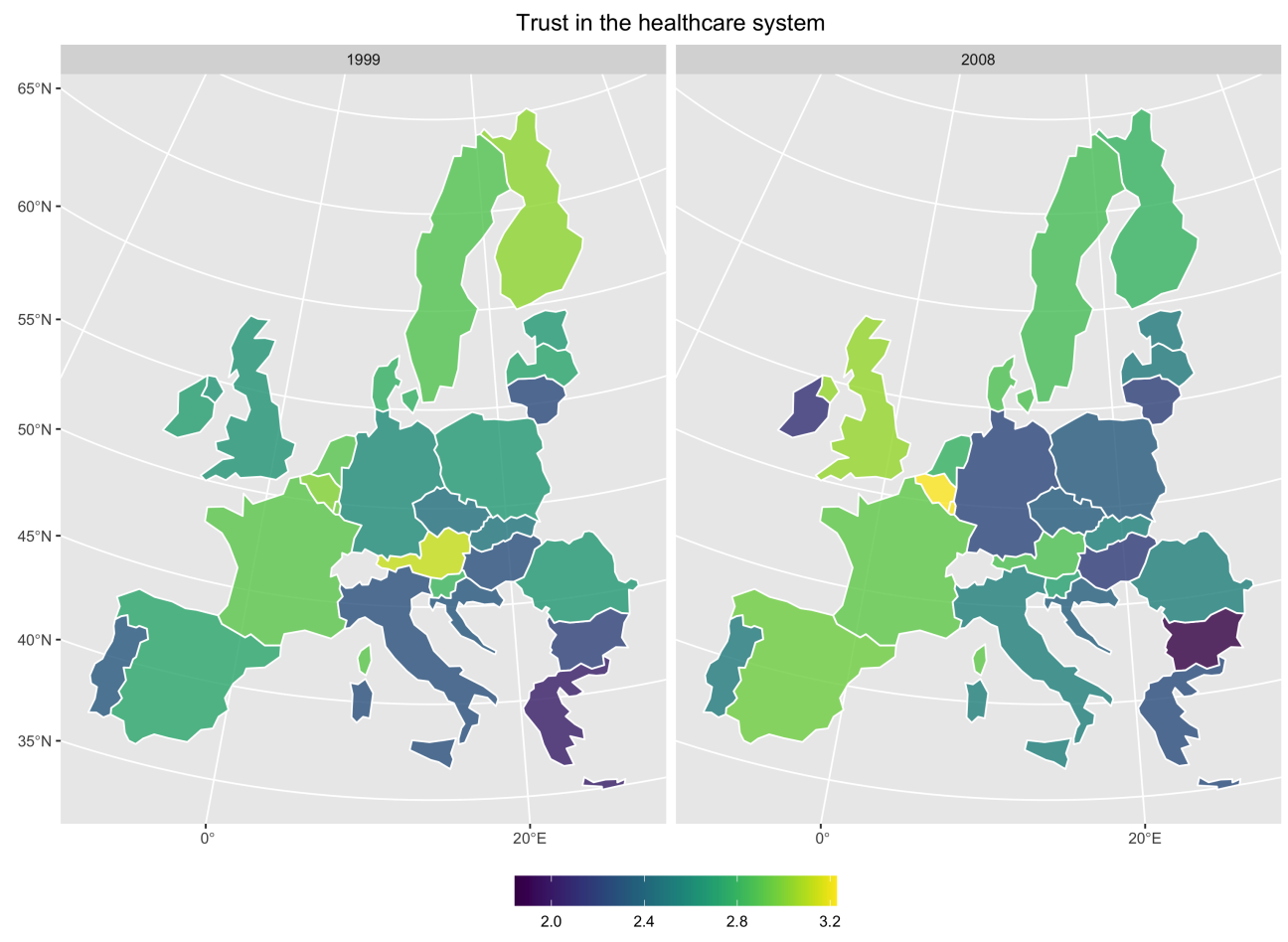

Figure S 2: Maps of trust in the healthcare system over time. There are two time points for which data is available $(1999 ; 2008)$. 


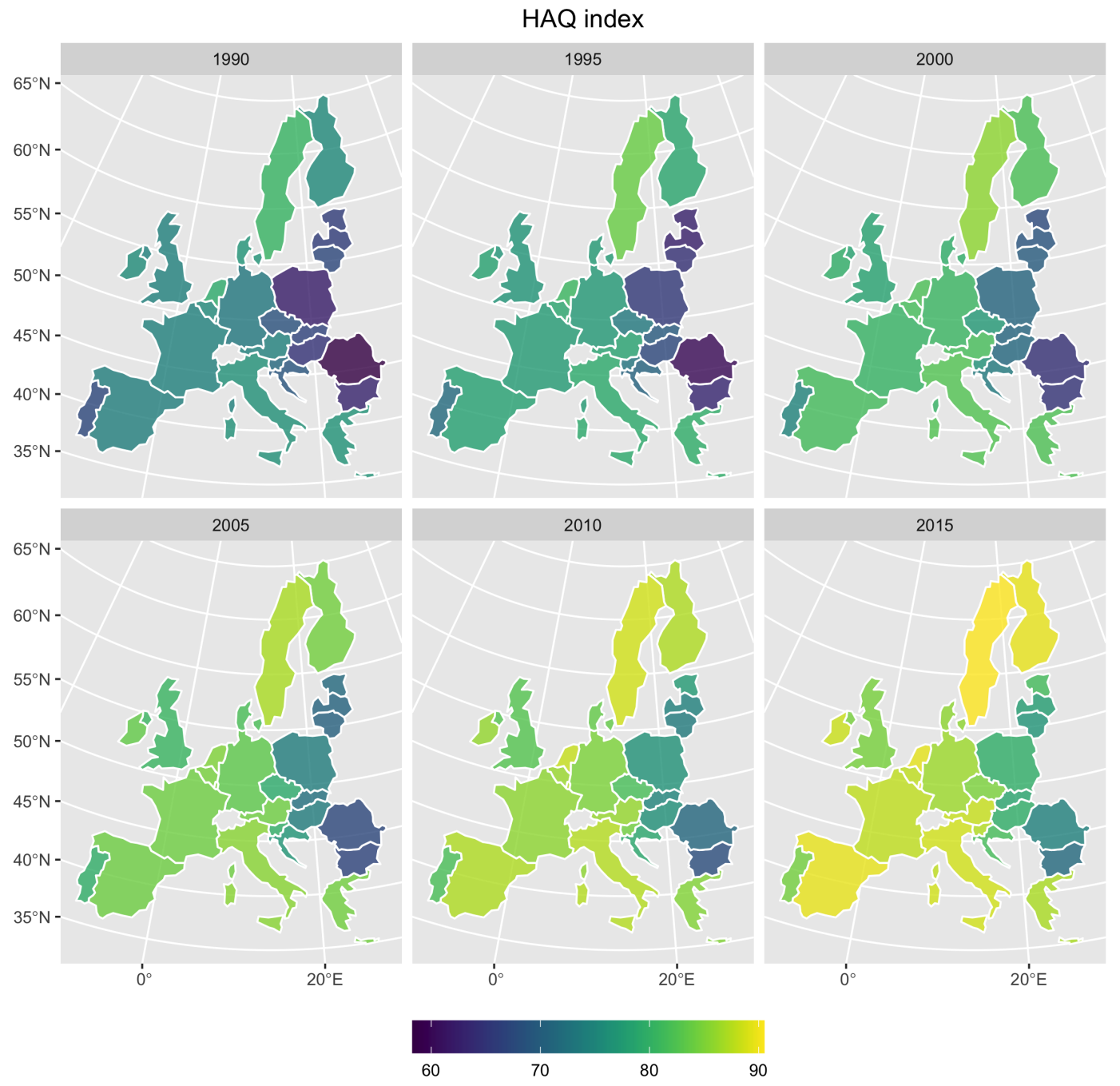

Figure S 3: Maps of healthcare quality in terms of HAQ index over time. There are six time points for which data is available $(1990 ; 1995 ; 2000 ; 2005 ; 2010 ; 2015)$. 


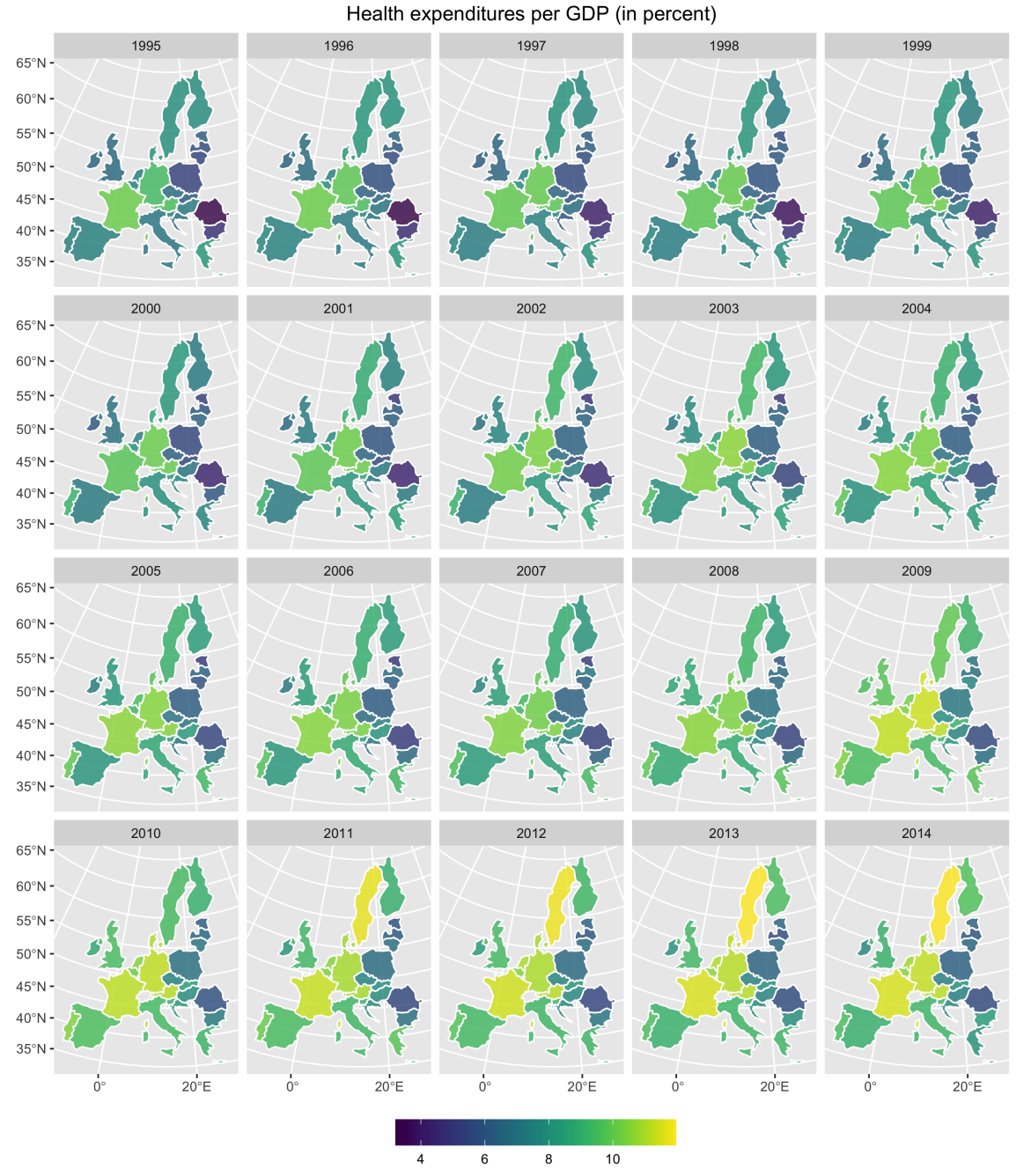

Figure S 4: Maps of healthcare quality in terms of healthcare expenditures per GDP (in percent) over time. There are 20 time points for which data is available (1995 - 2014, yearly). 


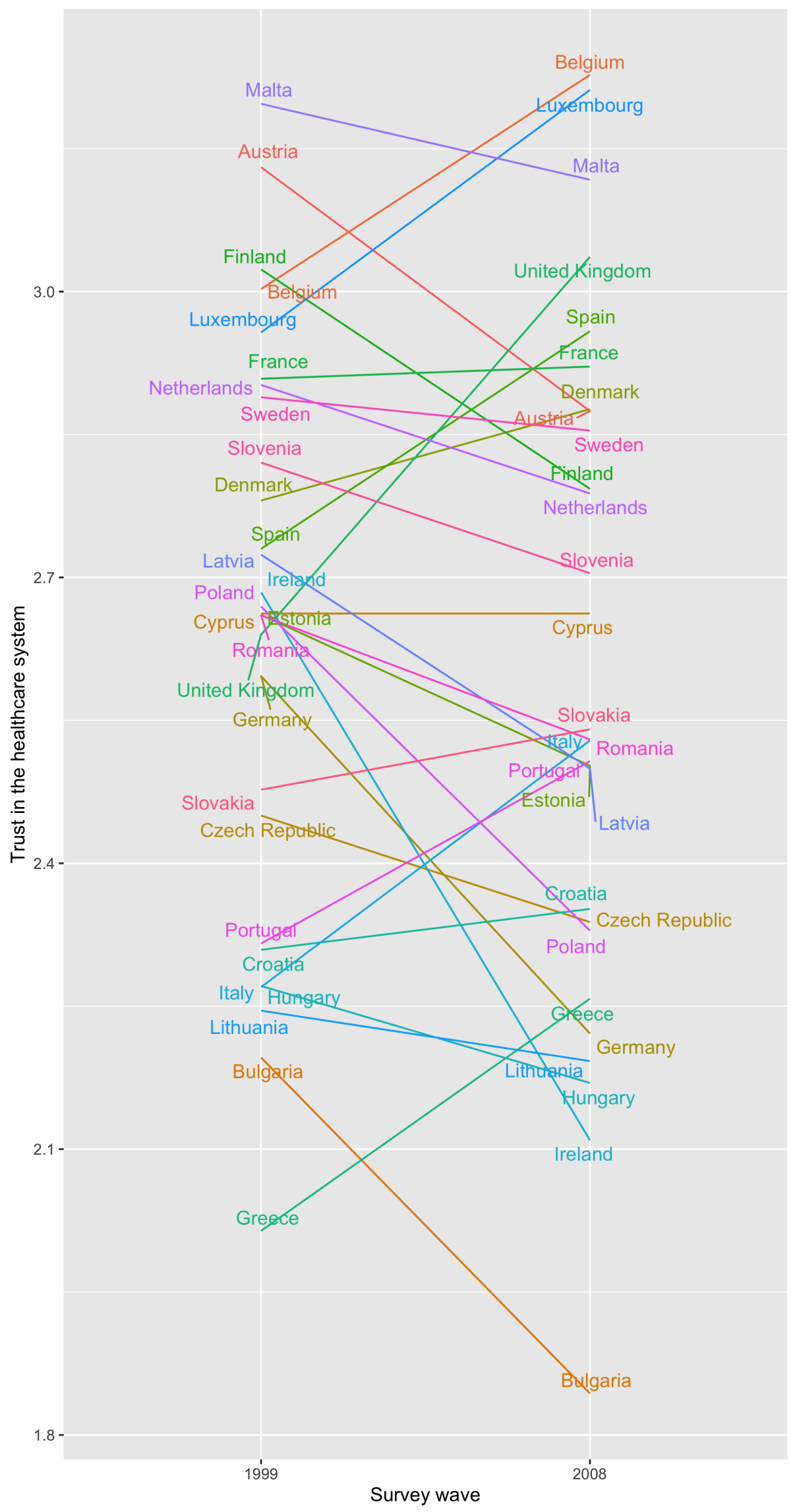

Figure S 5: Line chart displaying country-level trust $\mathrm{x}_{\text {in }}$ the healthcare system across the two survey waves. 


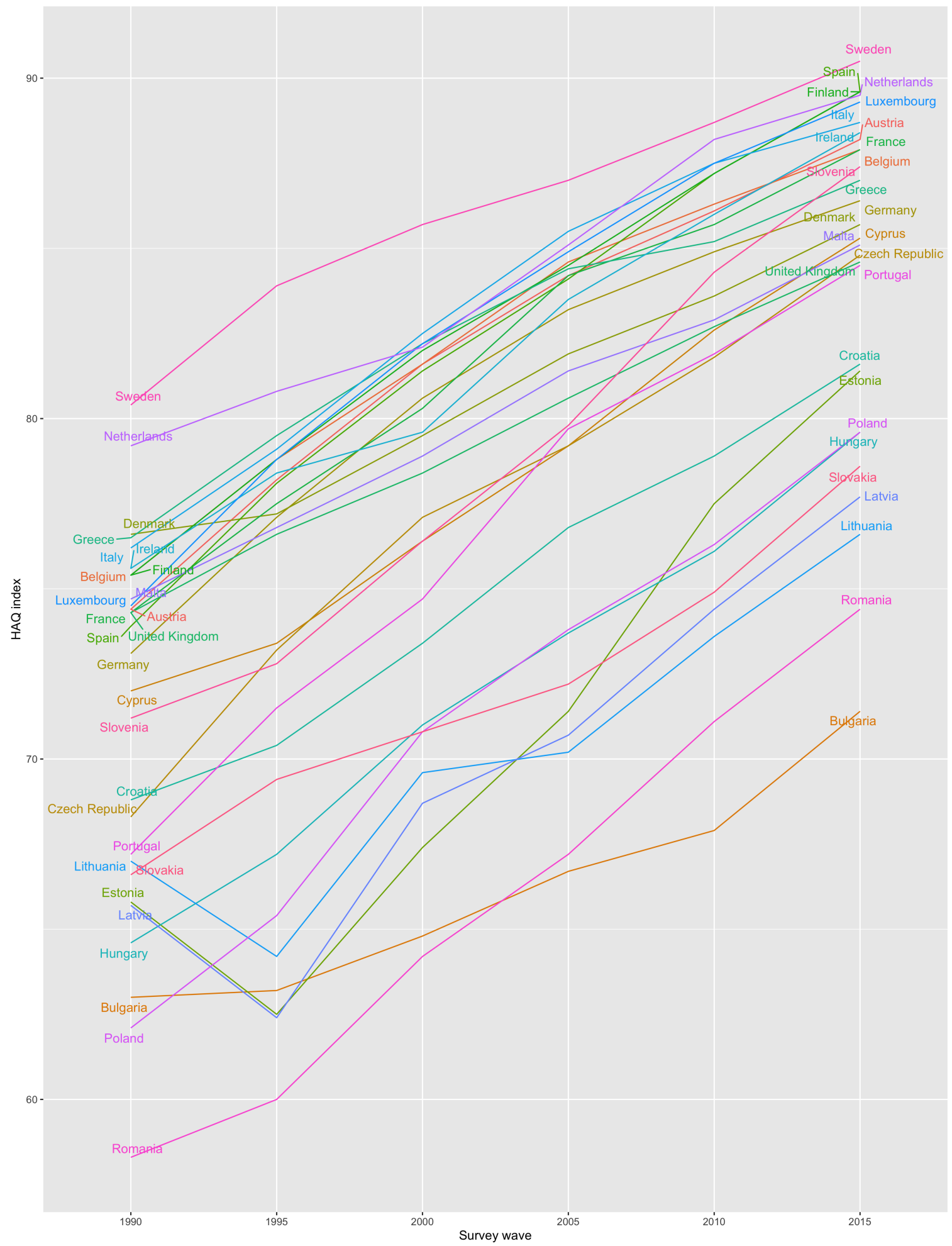

Figure S 6: Line chart displaying country-level scores of the HAQ index across the six survey waves. 


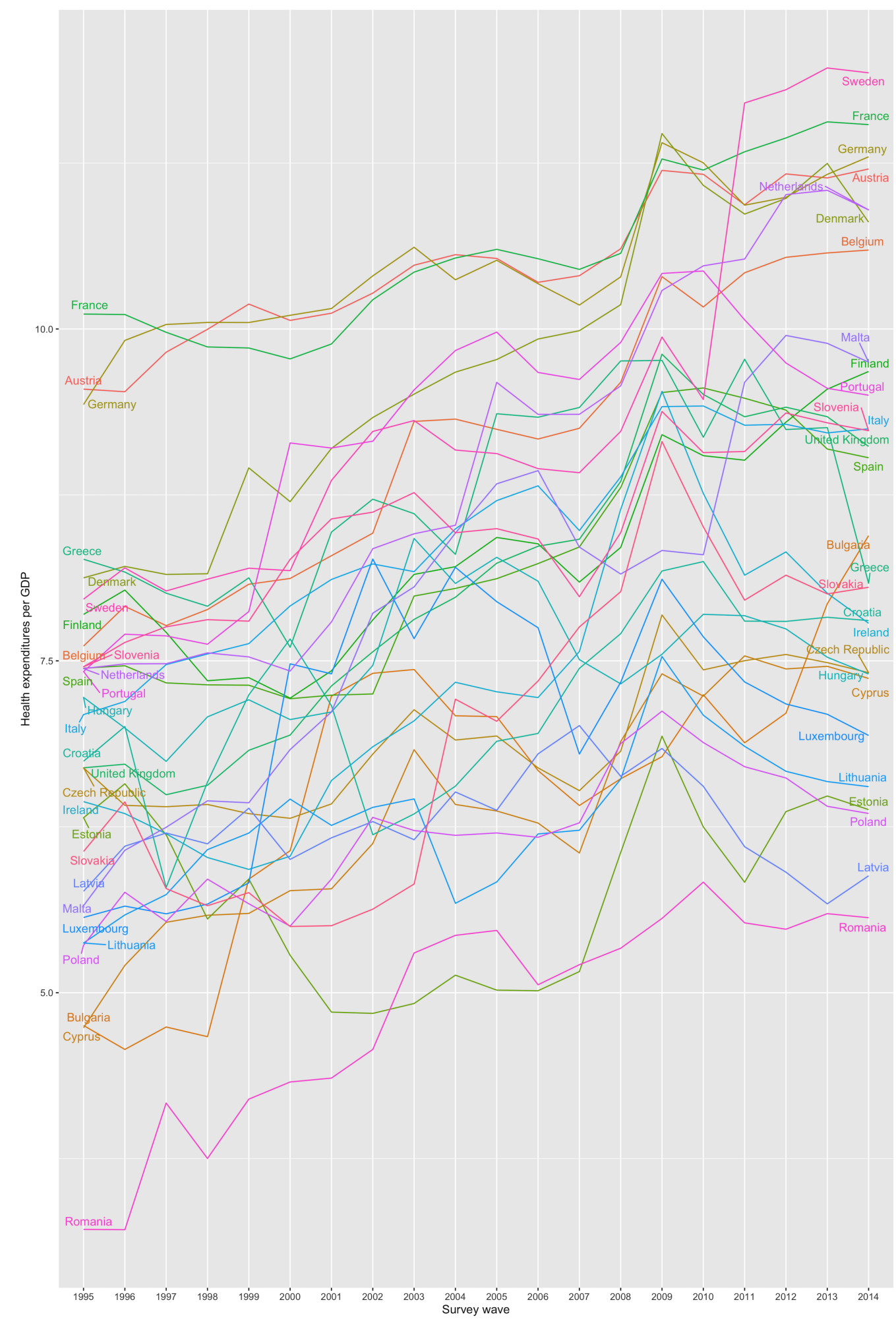

Figure S 7: Line chart displaying country-level healthcare expenditures per GDP across the 20 survey waves. 


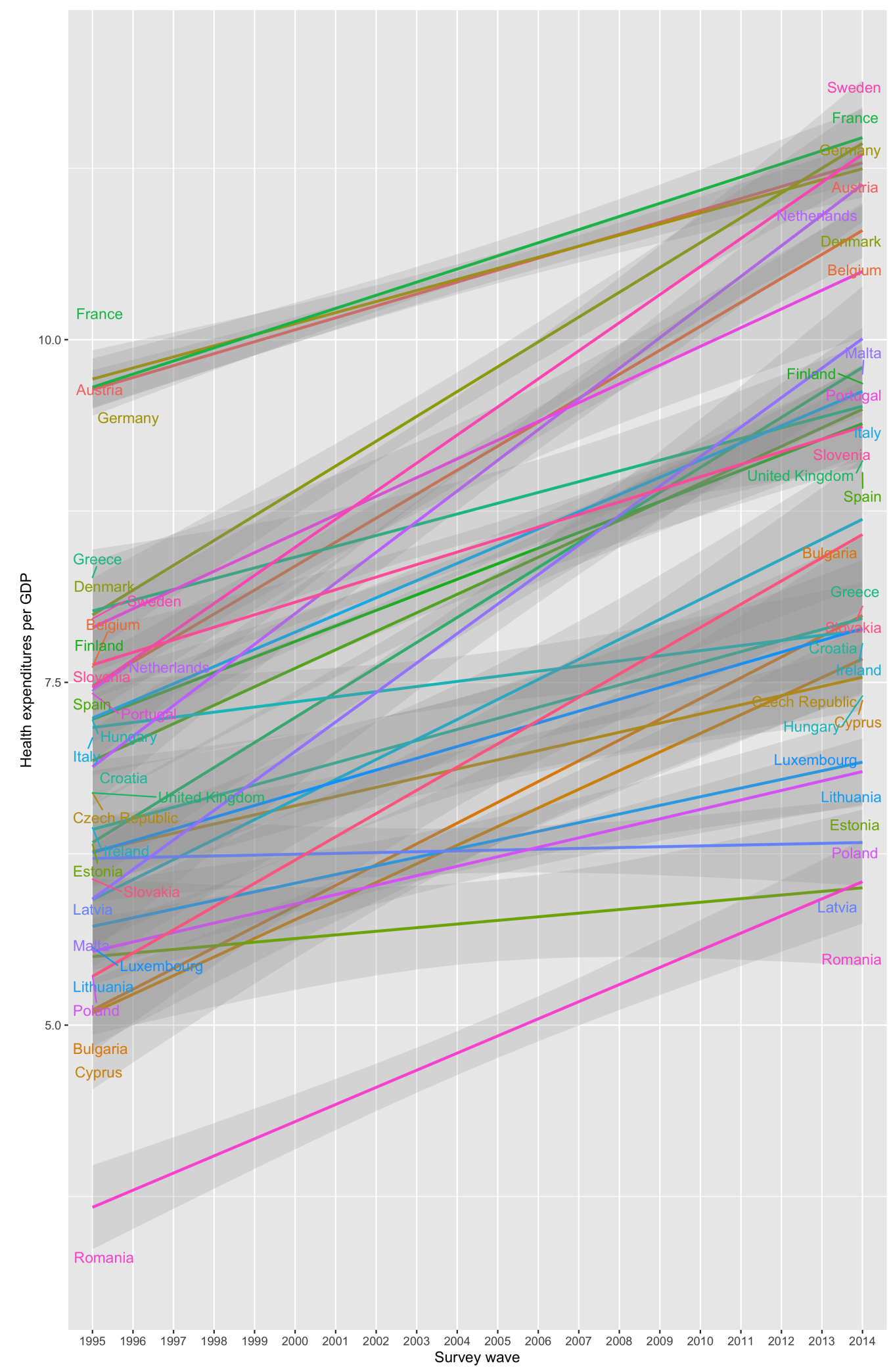

Figure S 8: Line chart displaying country-level healthcare expenditures per GDP at different survey time points. Straight lines are obtained by applying Lowess smoothing. 

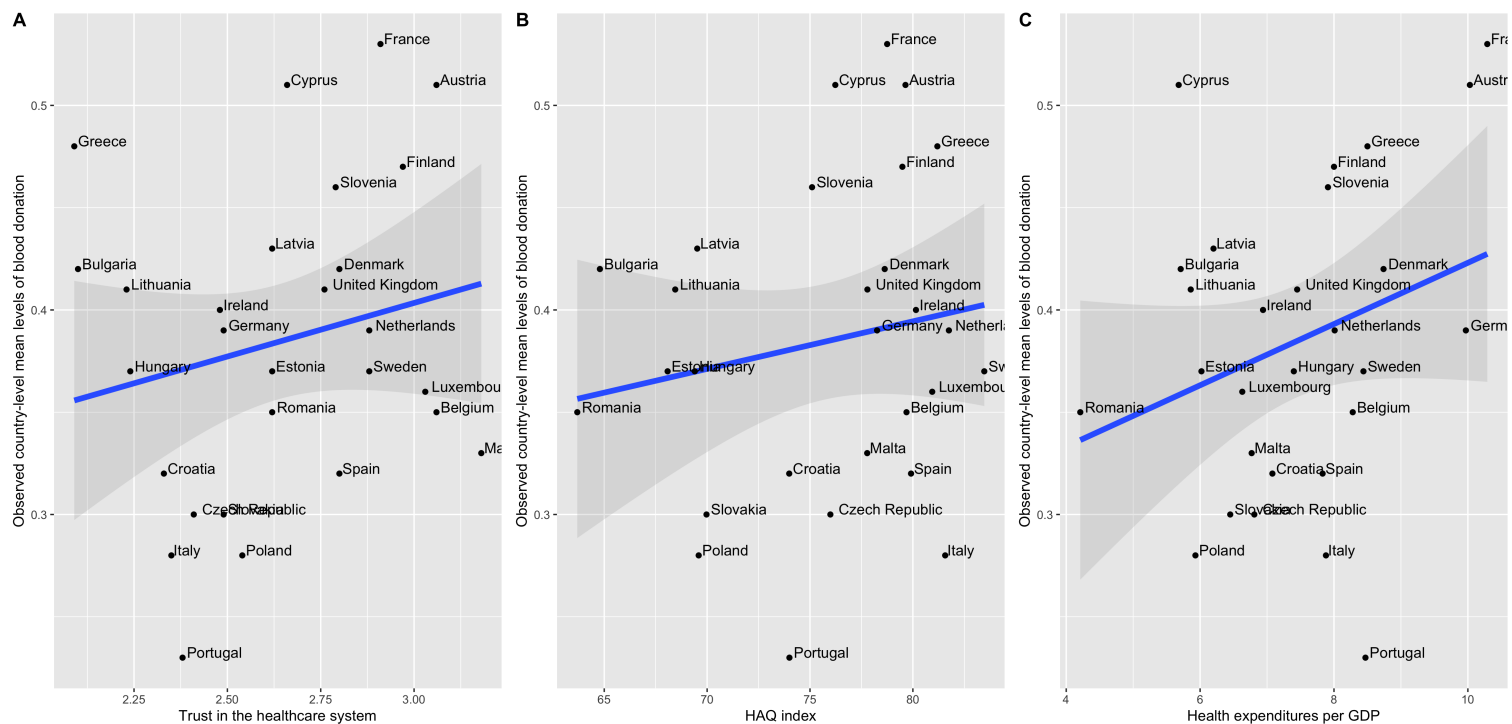

Figure S 9: Country-level mean levels of blood donation plotted against country-level mean indicator values. (A) Trust in the healthcare system. (B) Healthcare quality as measured by the HAQ index. (C) Healthcare quality as measured by healthcare expenditures per GDP.

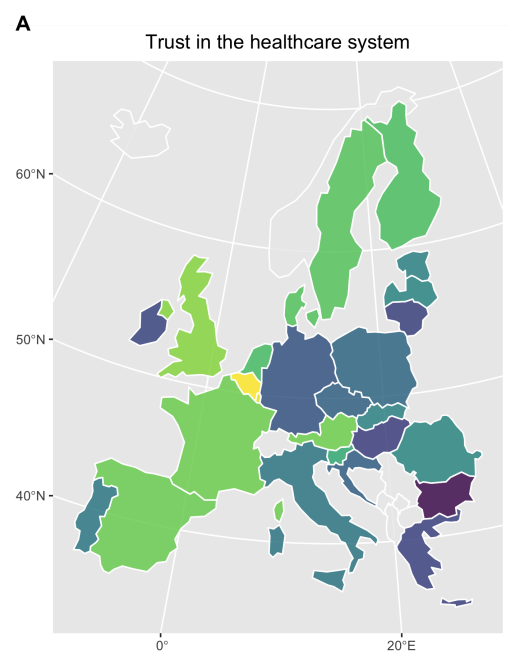

\begin{tabular}{lll}
\hline & & \\
2.0 & 2.4 & 2.8
\end{tabular}

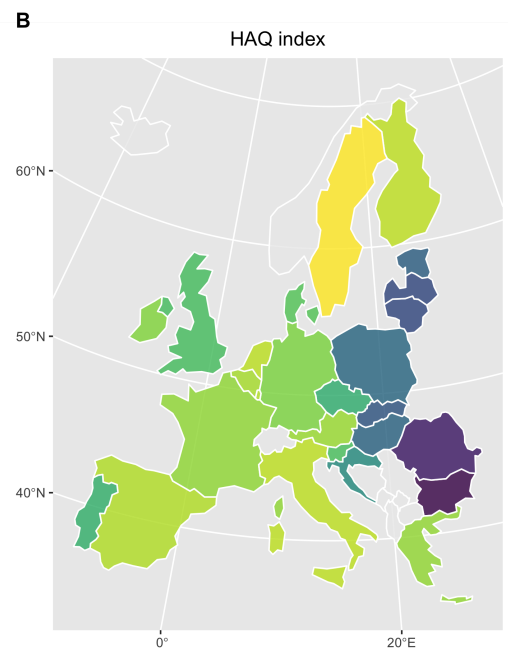

\begin{tabular}{lllll}
\hline 68 & 72 & 76 & 80 & 84
\end{tabular}

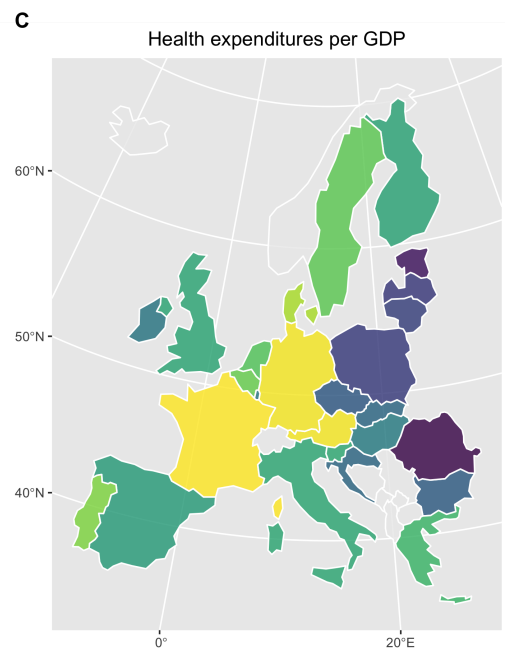

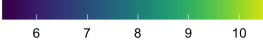

Figure S 10: Maps displaying trust in the healthcare system and quality of healthcare across Europe for the subsample of young respondents (age <44). (A) Trust in the healthcare system. (B) Healthcare quality as measured by the HAQ index. (C) Healthcare quality as measured by healthcare expenditures per GDP. 